\title{
Classification and management of epilepsy and epileptic syndromes in a cohort of 202 school children- a 2 year follow up study- Sudan
}

Inaam N. Mohamed ${ }^{1,2^{*}}$, Maha A. Elseed ${ }^{1,2}$, Somia Mohamed², Ali Alsir ${ }^{3}$, Emtinan K. Hamid ${ }^{4}$, Ilham M. Omer ${ }^{1,3}$, Sara M. Elsadig ${ }^{5}$, Yasmin M. Gerais ${ }^{6}$, Abdelgadir H. Osman${ }^{7}$, Aisha M. Bakhiet ${ }^{7}$ and Ahlam A. Hamed ${ }^{1,3}$

\begin{abstract}
Background: In this paper, seizure types, and epilepsy syndromes are elucidated as per ILAE (2010) classification. A brief outline of the antiepileptic drug regimens used and the outcome of seizure control in a two -year period is presented. The applicability of the ILAE classification in resource limited countries has been revisited.

Methods: This is a descriptive prospective study, in which 202 patients were enrolled. The Cohort group was seen and evaluated by a pediatric neurologist at the Pediatric neurology Outpatients Department (OPD). Epilepsy was classified using the International League Against Epilepsy (ILAE) classification (2005-2009) report. All patients had an Electroencephalogram (EEG) at the start of the study, and this was repeated as deemed appropriate. Brain imaging (MRI) was done to patients when indicated. Treatment decisions were made by pediatric neurologists. Outcomes were categorized into four groups: fully recovered, well controlled, partially controlled and uncontrolled.

Results: The mean age is $10.5 \pm 2.7$ years. Male to female ratio was 1.7: 1. Thirty five (17.3\%) patients had generalized onset seizures, $46(2 \overline{2} .8 \%)$ had focal onset seizures, $104(51.5 \%)$ had a specific epilepsy syndrome, and 17(8.4\%) patients were unclassified. 170 (84.2\%) patients were on mono-therapy on their initial visit, 30(14.8\%) were on two Antiepileptic Drugs (AEDs) while two (1.0\%) patients were on poly-therapy. After 2 years; $155(76.7 \%)$ patients were on mono-therapy, 36(17.8\%) on two AEDs while ten were (4.0\%) on polytherapy. One eighty (88.2\%) patients were controlled. Fifteen (7.4\%) of them were off medication after being seizure free for 2 years. Twenty (9.8\%) have partial control, while two (1.0\%) patients were uncontrolled. Patients with focal epilepsy, those on polytherapy and those with abnormal imaging had poor prognosis.
\end{abstract}

Conclusions: The ILAE classification can be used in resource limited countries. Childhood epilepsies have a good prognosis provided they are well classified and treated.

Keywords: Classification, Management, Epilepsy, Follow up, Sudan

\footnotetext{
* Correspondence: inaamgashey@gmail.com

${ }^{1}$ Neurology Division, Department of pediatrics and Child Health Faculty of

Medicine, University of Khartoum, P. O. Box 102, Khartoum, Sudan

${ }^{2}$ Neurology Unit, Gafer Ibn Auf Specialized Hospital for Children, Khartoum,

Sudan

Full list of author information is available at the end of the article
}

(c) The Author(s). 2019 Open Access This article is distributed under the terms of the Creative Commons Attribution 4.0 International License (http://creativecommons.org/licenses/by/4.0/), which permits unrestricted use, distribution, and reproduction in any medium, provided you give appropriate credit to the original author(s) and the source, provide a link to the Creative Commons license, and indicate if changes were made. The Creative Commons Public Domain Dedication waiver (http://creativecommons.org/publicdomain/zero/1.0/) applies to the data made available in this article, unless otherwise stated. 


\section{Background}

The prevalence of epilepsy is particularly high in Africa with an estimated mean prevalence of 15 per 1000 [1] The World Health Organization (WHO) estimates that there are over 50 million people with epilepsy, of whom two-thirds are children living in Africa and one-fifth in sub-Saharan Africa. The actual data upon which these estimates are made is very scarce. Epilepsy has been identified as a health priority for school age children because of its' high psychosocial morbidity and the potential for control using low cost interventions [2].There have been relatively few studies of epilepsy in school age children in Sudan and most of these have given little information about seizure types [3] and the long-term outcome of these remains largely unknown. In this study classification of seizure types and the various epileptic syndromes according to ILAE (2010) classification was performed. This study also outlines the antiepileptic drug regimens used and the outcome of seizure freedom in a two- year period. The applicability of the ILAE classification in resource limited countries is assessed.

\section{Methods}

This is a descriptive prospective study conducted between 2016 and 2017. The sample size calculation was based on a previous survey conducted at Khartoum State in 2015 which identified 303 children out of 74,959 school children with epilepsy and the prevalence rate was reported as 4/1000. In Phase I of this study the epilepsy was initially classified into generalized, focal and unclassified [4].

\section{Case definition \\ Epilepsy}

A diagnosis of epilepsy in this study is retained if the patient had at least two or more epileptic seizures unprovoked by any immediate cause [1].

\section{Developmental impairment}

(US equivalent of mental retardation) can be static or progressive, recent or long standing, global or specific. It includes assessment of gross motor, fine motor, communication, vision, hearing, social and psychomotor skills [5].

\section{Motor delay}

Any delay in the acquisition of the motor skills that can easily be remembered by the parents like delayed neck control, sitting and walking [5].

\section{Speech delay}

Any delay in acquiring skills elated to the production and/ or perception of the oral symbols used for language [5].

\section{The cohort}

The present study was part of a population- based study of prevalence of epilepsy in school children in KhartoumSudan. However, 50(16.5\%) patients continued their follow-up in their locality or nearby clinics, 31(10.2\%) had incomplete clinical data so they were excluded. Eighteen (5.9\%) patients lost their follow up and we were unable to trace them while one $(0.3 \%)$ patient died following a road traffic accident. In this study, we report on 202 patients whose follow up continued for 2 years.

The cohort group was seen and evaluated by the Pediatric neurologists $1 \& 2$ at the OPD at Fath El- Rahman El-Basher Center; the referred clinic for Gafer Ibn Auf Specialized Hospital for children in Khartoum- Sudan.

\section{Epilepsy classification}

For each patient, epilepsy was classified using the ILAE Commission on classification and terminology 2005-2009 Report [6]. Factors considered in the classification included seizure type (s) based on descriptive semiology and personal interview; however supportive information such as video recording of the event, EEG and neuroimaging findings were also utilized [2]. Patients were further classified into individual specific syndromes if applicable, based on ILAE criteria and age at onset and seizure semiology. Specific syndrome designation was assessed both at initial presentation and at prospective follow-up.

\section{Investigations}

All patients had an EEG at the start of the study, and that was repeated as deemed appropriate. The EEGs were done using the 10-20 system with photic stimulation and hyperventilation procedures done when indicated; none of the patients had undergone a video-telemetry EEG or an ambulatory EEG recording as these are unavailable in the study setting The majority of patients (89\%) had sleep EEGs (induced by chloral-hydrate) and very few EEGs were done whilst awake or sleep deprived. The EEGs were interpreted and reported by an adult neurophysiologist with special interest in pediatrics EEGs.

The MRI was the modality of brain imaging requested as and when indicated. The MR imaging studies were performed at different centers, where the imaging protocols were variable. All images of patients in this study included at least one sagittal view and one axial sequence $1.5 \mathrm{~T}$. All patients were studied with T1-T2 and FLAIR -weighted sequences. The final report was that agreed by the radiologist who finally reviewed all the images. MRI of the brain was done for patients with any impairment in development, those suspected to have behavioral and/or educational problems, those with focal seizures associated with focal neurological deficit and for patients with uncontrolled seizures. 


\section{Treatment}

Treatment decisions were made by pediatric neurologists as per the international recommendations for the specific seizure type, taking into consideration the age of the patient, sex, tolerability, formulations, availability and affordability of AEDs in our setting. Other modalities of treatment e.g. ketogenic diet and epilepsy surgery are not available in Sudan. We tried at least two first-choice AEDs in mono-therapy (mostly Sodium Valproate and Carbamazepine) before using a polytherapy regimen. In children who experienced 2 years free of seizures, the $\operatorname{AED}(\mathrm{s})$ were withdrawn gradually.

\section{Follow up and outcome}

The majority of patients were seen three-monthly to check for seizures frequency, duration, drug side effects and dose adjustments of the AEDs. However, some patients were seen more frequently on an individual basis, especially if they have refractory seizures and/or other co-morbidities For the purpose of this study, the outcomes were categorized into four main groups; 'Fully recovered'- if no seizures occurred for the last 2 years and AEDs were tapered, 'Good' controlled if seizures occur less than once per month. 'Partial seizure- control' if there is a decrease in seizure frequency and duration by more than $50 \%$ with seizures occurring every month (but not every week) during the last 6 months and lastly an 'Uncontrolled group' if there is no change in the seizure frequency, if it is decreased by less than $50 \%$ in the last 6 months or got worse.

\section{Variables}

Sex, age at onset of seizure, perinatal history, family history of epilepsy, epilepsy types, number of AEDs, MRI/ Brain findings were used as determinant to outcome.

\section{Data analysis}

Data analysis was performed using SPSS software package version 23. The quantitative variables were presented as mean and standard deviation. Qualitative variables were described in the form of frequency and percentage. Standard test of significance (Chi-Square Test) was used. $P$-value was considered significant if its value is less than 0.05 .

\section{Results}

The study included 202 patients with epilepsy, with an age range of $6-14$ years. The mean age is $10.5 \pm 2.7$ years. The majority $101(49.5 \%)$ were more than 10 years of age. One hundred ninety (94.05\%) were known to have epilepsy while $12(5.95 \%)$ were newly diagnosed. One hundred twenty six (62.4\%) were male and 76(37.6\%) were female with a ratio of 1.7: 1 .

Forty eight (23.8\%) had prenatal complications of whom 21(43.7\%) suffered from Pregnancy Induced Hypertension (PIH), 15(31.3\%) were affected by gestational diabetes, nine (\%18.7) had complications related to Intrapartum haemorrhage and three (6.25\%) were suffering from Oligohydramnios. The majority $-195(96.5 \%)$ of the study group were delivered at term, five $(2.4 \%)$ were preterm and two $(1.1 \%)$ were postdates. Seventeen $(8.4 \%)$ patients had developmental impairment during early childhood, the majority $10(58.8 \%)$ had isolated motor impairment and seven (41.2\%) had speech delay. All of them had brain atrophy on their brain images. Visual problems were reported in $12(5.9 \%)$ patients and Hearing impairment in four (1.9\%) patients. Consanguinity (first degree maternal/ or paternal cousin) rate was found to be $54 \%$ and $69(34.2 \%)$ patients had a positive family history of epilepsy (sibling or first degree cousin).

Thirty four (16.8\%) patients had seizure onset before the age of 1 year, $49(24.1 \%)$ between 1 and 5 years, $81(40.1 \%)$ between 5 and 10 and $38(18.8 \%)$ had seizures onset after the age of 10 years.

The EEG background was normal in all patients. Generalized epileptiform discharges were recorded in the EEG of 61 (30.2\%) patients, 88(43.6\%) had focal seizure discharges. Fifty three (26.2\%) patients had no evidence of epileptiform discharges in their first EEG of whom $20(37.7 \%)$ demonstrated evidence of epileptiform activity in the second EEG when done with sleep deprivation.

MRI of the brain was done to $118(58.4 \%)$ patients, it was abnormal in 65(55.1\%), of whom $29(24.5 \%)$ had diffuse brain atrophy, $11(9.3 \%)$ had Mesial temporal sclerosis(MTS), seven (5.9\%) had thin corpus callosum, five (4.2\%) had evidence of infarction, four (3.3\%) had congenital arachnoid cyst, four(3.3\%) had hydrocephalus (with VP shunt) three(2.5\%) had arrested hydrocephalus and three $(2.5 \%)$ had hemi-atrophy.

One hundred eighty five (91.5\%) patients had their initial epilepsy classification revised after history, clinical examination, EEG findings and the result of the MRI of the brain in addition to other investigations.

Thirty-five (17.3\%) patients had generalized onset seizures, $46(22.8 \%)$ had focal onset seizures, $104(51.5 \%)$ had a specific epilepsy syndrome, and 17(8.4\%) patients had unclassified seizures. Each group was further reclassified (Table 1).

One hundred and seventy (84.2\%) patients were on mono-therapy on their initial visit, $30(14.8 \%)$ were on two AEDs while two (1.0\%) patients were on polytherapy. The most commonly used AEDS was Sodium Valproate (used by 130 (64.3\%) patients) followed by Carbamazepine 87(43.0\%), Phenbarbitone 19 (9.4\%) and four $(1.9 \%)$ patients on Topiramate.

At the initial evaluation visit $42(20.8 \%)$ patients had good seizure control, 50(24.8\%) had partial control (decrease in seizure frequency and duration by more than $50 \%)$ while $110(54.4 \%)$ had uncontrolled seizures (No change in seizure frequency or duration, or decreased by less than $50 \%$ ). 
Table 1 Classification of epilepsy among the study group $(n=202)$

\begin{tabular}{|c|c|c|}
\hline \multicolumn{2}{|l|}{ Epilepsy classification } & \multirow{2}{*}{$\frac{\text { Number (\%) }}{15(07.4)}$} \\
\hline Generalized 35(17.3\%) & Generalized Tonic - Clonic & \\
\hline & Myoclonic & $11(05.4)$ \\
\hline & Tonic & 07(03.5) \\
\hline & Atonic & 02(01.0) \\
\hline \multirow[t]{3}{*}{ Focal $46(22.8 \%)$} & Simple Focal & 05(02.5) \\
\hline & Complex focal & 15(07.4) \\
\hline & Focal evolving into Generalized Seizure & 26(12.9) \\
\hline \multirow[t]{9}{*}{ Epilepsy syndrome 104(51.5\%) } & Epilepsy with Centrotemporal Spikes(ECTS) & $25(12.4)$ \\
\hline & Childhood Absence Epilepsy (CAE) & 23(11.4) \\
\hline & Juvenile Absence Epilepsy (JAS) & 19(09.4) \\
\hline & Juvenile Myoclonic Epilepsy (JME) & 15(07.4) \\
\hline & Frontal lobe Epilepsy & 07(03.5) \\
\hline & Late-onset childhood occipital epilepsy & 07(03.4) \\
\hline & Epilepsy with Myoclonic Absence seizures & 04(02.0) \\
\hline & Hemi- convulsion-Hemiplegia-Epilepsy & $03(01.5)$ \\
\hline & Eyelid Myoclonia with Absence Seizures & $01(0.5)$ \\
\hline Unclassified 17(8.4\%) & $17(8.4 \%)$ & 17(08.4) \\
\hline Total & & $202(100 \%)$ \\
\hline
\end{tabular}

After 2 years; $155(76.7 \%)$ patients were on monotherapy, 36(17.8\%) on two AEDs while ten (4.0\%) on polytherapy. The commonly used AED 90(44.5\%) was Sodium Valproate followed by Carbamazepine 60(29.7\%), Levetiracetam $57(28.2 \%)$ and Lamotrigene in $40(19.8 \%)$ patients. Fifteen $(7.4 \%)$ patients fully recovered, 165(81.7) were well controlled, twenty $(9.8 \%)$ had partial control, while two (1.0\%) patients were uncontrolled (Table 2).

The correlation between seizure control and other variables was tested using Chi-Square Test and $P$-value was considered significant if it is less than 0.05 . There were no significant differences between males and females, age at onset of seizures, family history of epilepsy and whether there is evidence of birth asphyxia repetition $(\mathrm{P}$ - value $=0.1,0.1,0.23,0.2)$ respectively.

Using Chi- Square test, patients on mono-therapy showed good seizure control when compared to those on two or more AEDs (P- value $=0.01$ ). Patients with generalized seizures showed better control in comparison to those with focal seizures and epilepsy syndromes $(p$ value $=$ 0.002). Patients who had normal MRIBrain imaging had good seizure control and vice versa. $(\mathrm{P}$ - value $=0.01)$.

\section{Discussion}

There is insufficient data on the prevalence of epilepsy syndromes in our population and their long term effects on the development and educational trajectories of these patients. Accurate classification of epilepsy type and specific syndromes is paramount as long-term outcome is largely determined by the underlying epilepsy syndrome.
Table 2 Treatment and response to AEDs at initial visit and 2years after among the study group $(n=202)$

\begin{tabular}{lll}
\hline & Initial Visit & After 2 years \\
\hline Anti-Epileptic Drugs (AEDs) Treatment & \\
Mono therapy & $170(84.2 \%)$ & $150(76.7 \%)$ \\
Two drugs & $30(14.8 \%)$ & $36(17.8 \%)$ \\
polytherapy & $02(1.0 \%)$ & $10(4.0 \%)$ \\
Anti-Epileptic Drugs (AEDs) & & \\
Sodium Valproate & $130(64.3 \%)$ & $90(44.5 \%)$ \\
Carbamazepine & $87(43.0 \%)$, & $60(29.7 \%)$ \\
Lamotrigene & 0.0 & $40(19.8 \%)$ \\
Levetiracetam & 0.0 & $57(28.2 \%)$ \\
Phenbarbitone & $19(9.4 \%)$ & 0.0 \\
Topiramate & $04(1.9 \%)$ & 0.0 \\
Others & $04(1.9 \%)$ & $15(7.4 \%)$ \\
Response to AEDS & & \\
Fully recovered & 0.0 & $15(7.4)$ \\
Good control & $42(20.8)$ & $165(81.7)$ \\
Partially control & $50(24.7)$ & $20(9.9)$ \\
Uncontrolled & $110(54.4)$ & $02(1.0 \%)$ \\
Total & $202(100)$ & $202(100)$ \\
\hline
\end{tabular}


With optimal classification and management, around $70 \%$ of the patients will enter remission. In the long term, antiepileptic drugs can be discontinued in almost half of affected individuals [7]. This relatively good prognosis contrasts with persistent public stigma surrounding the condition especially in our setup [8].

Using ILAE classification (2010), we were able to classify $91.6 \%$ of epilepsies and epileptic syndromes. This was similarly reported by Eiji Oka et al. from Japan and Matti Sillanpää et al. from Finland who stated that (91\%) of the patients (under 16 years) could be classified using $\operatorname{ILAE}(1989)[9,10]$.

Almost half of the patients in the study had focal onset seizures a finding that is similar to the results from subSaharan Africa [11-14] and even a higher rate was reported from rural Kenya, in which $71 \%$ of the patients had evidence of focal onset seizures [15]. A previous report from Sudan [3] stated a higher percentage of focal-onset seizures as well. Focal seizures may still be higher in this study if more detailed investigations such as video telemetry and functional imaging (PET or SPECT) are used, which will ultimately improve the localization of epileptiform activity.

The commonest epilepsy syndrome in this study was ECTS, which was noted in $12.4 \%$ of patients. High prevalence of ECTS was also found in studies from Sweden and Italy [16-18] whereas lower frequencies were found in Israel [19]. Literature reports of frequency distribution of other epilepsies and epilepsy syndromes seem to vary considerably.

Several reports, including this study, have highlighted the relatively high frequencies of additional neurological deficits in children with epilepsy [19,20]. In this study 8.4\% patients had developmental impairment with brain atrophy on imaging. This group is likely to have a yet undiagnosed genetic/metabolic cause which is most likely the cause of both the epilepsy and the developmental impairment. Due to the lack of CGH microarray and Whole exome sequencing (WES) tests in our setting, the exact etiology in this group remains largely unknown.

Over the last decade; epidemiological studies have demonstrated that the prognosis of many childhood epilepsies is more favorable with $70-80 \%$ eventually reaching remission [21]. The prognosis of many patients in this study was good, with overall remission rates of $81.4 \%$ in comparison to a rate of $70-80 \%$ which has been reported by Tidman et al. [22]. The proportion of children who were resistant to therapy was $1 \%$ which is low when compared to Camfield et al. [23] and Elaine C et al. reports [24]. In this study, epilepsy prognosis is poor amongst patients with focal onset seizures, those on polytherapy and those with abnormal brain image when compared to those with generalized onset epilepsy and those on mono-therapy. Brorson LO et al. from
Sweden reported on Long-term prognosis(12 years) in childhood epilepsy and concluded that patients with neuro-deficits had a poorer outlook [25] There was a higher probability of seizure freedom in patients receiving mono-therapy when compared to those on two AEDs or polytherapy which is similar to a report by Arts WF1 et al. [26].

Due to mounting evidence that Phenbarbitone and Topiramate can negatively impact the cognitive function in this subset of children, both were tapered and alternatives were offered [27, 28]. Alternatively, some patients were started on Levetiracetam and Lamotrigene based on recent evidence that they are the ones least likely to interfere with cognitive processes [27]. A few female patients who were initially on Sodium Valproate were shifted to Levetiracetam due to side effects mainly weight gain and hair loss and also to comply with the prevent program of avoiding Valproate in females of child bearing age.

\section{Conclusions}

The ILAE classification can be used in resource limited countries. Childhood epilepsies have a good prognosis if well classified and treated. Further studies are needed to review long term remission, probability of recurrence after AEDs withdrawal and the impact of seizures on school performance and behavior.

\section{Abbreviations}

AEDs: Antiepileptic Drugs; CAE: Childhood Absence Epilepsy; CT-

Scan: Computed Tomography Scan; ECTS: Epilepsy with Centro-temporal Spikes; EEG: Electroencephalogram; JAE: Juvenile Absence Epilepsy; JME: Juvenile Myoclonic Epilepsy; MRI: Magnetic Resonance Image; WHO: World Health Organization

\section{Acknowledgements}

Our great thanks to all children and their caregivers who participated in this study.

\section{Authors' contributions}

IN: Prepared the Concept paper, designed the questionnaire, filling and interview of patients, taking care of patients' management and follow up, data analysis, drafted manuscript, publication process and fundraising. MA: Interview of patients, taking care of patients' management and follow up data, drafted and edited manuscript. SM: Filling the questionnaire and interview of patients, taking care of patients' management and follow up data. Data entry and analysis. AF: filling the questionnaire and interview of patients, taking care of patients' management and follow up data. Raising fund. EK: Study design, Data entry and Data analysis. IM: Literature search, concept paper and editing the manuscript. SM: Filling the questionnaire and interview of patients, taking care of patients' management and follow up data. YA: Filling the questionnaire and interview of patients, taking care of patients' management and follow up data. AH: concept paper, study design and literature search. AM: Concept paper, literature search and data entry. AA: Concept paper and literature search, filling the questionnaire and interview of patients, taking care of patients' management and follow up data. All authors read and approved the final manuscript.

Funding

Ministry of Higher Education and Research-Sudan. 


\section{Availability of data and materials}

The dataset used and analyzed during the current study is available from the corresponding author on reasonable request.

\section{Ethics approval and consent to participate}

Ethical approval was obtained from Research and Ethical Committee at Faculty of Medicine -University of Khartoum. This study is part of an epidemiological study for epilepsy among school children in Sudan. Phase of this study addressed the prevalence of epilepsy among school children in Khartoum State. A confidential letter was sent to the parents of each patient identified, explaining the aims of the study and providing information on the research group. The letter was brought to their first appointment at the epilepsy (OPD) at Gafer Ibn Auf Specialized Hospital for children and acted as an informed written consent. Upon follow up of these patients for 2 years we explain the aim of this phase in simple Arabic language and their verbal consent was taken as they have had already given the consent for the whole project earlier. All doctors taking care of any of the patients amongst our study group were approached and verbal permission was taken as to have the freedom to change the patient's epilepsy classification and management, if indicated, and a feedback including the plan of management was sent to those who continued to follow up the patients in their own clinics.

\section{Consent for publication}

Not applicable.

\section{Competing interests}

The authors declare that they have no competing interests.

\section{Author details}

${ }^{1}$ Neurology Division, Department of pediatrics and Child Health Faculty of Medicine, University of Khartoum, P. O. Box 102, Khartoum, Sudan. ${ }^{2}$ Neurology Unit, Gafer Ibn Auf Specialized Hospital for Children, Khartoum, Sudan. ${ }^{3}$ Neurology Unit, Soba University Hospital, Khartoum, Sudan. ${ }^{4}$ Department of community, Faculty of Medicine, University of Khartoum, Khartoum, Sudan. ${ }^{5}$ Department of Medicine, Faculty of Medicine, University of Khartoum, Khartoum, Sudan. ${ }^{6}$ Ministry of Health, Khartoum, Sudan. ${ }^{7}$ Department of Psychiatry, Faculty of Medicine, University of Khartoum, Khartoum, Sudan.

Received: 16 April 2019 Accepted: 27 October 2019

Published online: 15 November 2019

\section{References}

1. Shlomo Shinnar John M. Update on the Epidemiology and Prognosis of Pediatric Epilepsy. J Child Neurol. 2002. https://doi.org/10.1177/ 08830738020170010201.

2. The World Health Report, 2001. Mental health: new understanding, new hope. 1st ed. Geneva: WHO; 2002

3. Mohammed IN, Elssed MA, Rahman AA. The profile of childhood epilepsy in Sudan. KMJ. 2010;2:444-7.

4. Mohamed IN, Elseed MA, Hamed AA, AbdelRahman ME, El-Sadig SM, Iham M, et al. Prevalence of epilepsy in 74,949 school children in Khartoum state, Sudan. Paediatrics and International Child Health. 2017;37:188-92.

5. Bax M, Goldstein M, Rosenbaum P, Leviton A, Paneth N, Dan B, et al. Proposed definition and classification of cerebral palsy. Dev Med Child Neurol. 2005:47:571-6.

6. Anne T, Samuel B, Berkovic MJ, Buchhalter J, Cross H, et al. Revised terminology and concepts for organization of seizures and epilepsies: report of the ILAE commission on classification and terminology, 2005-2009. Epilepsies. 2010;5:676-85.

7. Bernd A. Neubauer, Stephanie Gro, Andreas Hahn. Epilepsy in Childhood and Adolescence Medicine 2008; 105:319-28.

8. Mohamed IN, Babeker H. Traditional and spiritual medicine among Sudanese patients with epilepsy. Sudanese Journal of Paediatrics. 2013:13:31-7.

9. Oka E, Ohtsuka Y, Yoshinaga H, Murakami N, Kobayashi K, Ogino T. Prevalence of Childhood Epilepsy and Distribution of Epileptic Syndromes: A Population-based Survey in Okayama, Japan. Epilepsia. 2006;47:626-30.

10. Sillanpää M, Jalava M, Shinnar S. Epilepsy syndromes in patients with childhood-onset seizures in Finland. Pediatr Neurol. 1999;21:533-7.
11. Burton K, Rogathe J, Whittaker R, Mankad K, Hunter E, Burton MJ, et al. Epilepsy in Tanzanian children: association with perinatal events and other risk factors. Epilepsia. 2012;53:752-60.

12. Dent W, Helbok R, Matuja WB, Scheunemann S, Schmutzhard E. Prevalence of active epilepsy in a rural area in South Tanzania: a door to-door survey. Epilepsia. 2005;46:1963-9.

13. Edwards T, Scott AG, Munyoki G, Odera VM, Chengo E, Bauni E, Kwasa T, et al. Active convulsive epilepsy in a rural district of Kenya : a study of prevalence and possible risk factors. Lancet Neurol. 2008;17:50-6.

14. Mung'ala-Odera V, White S, Meehan R, Otieno GO, Njuguna P, Mturi N, et al. Prevalence, incidence and risk factors of epilepsy in older children in rural Kenya. Seizure. 2008;17:396-404.

15. Munyoki G, Edwards T, White S, Kwasa T, Chengo E, Kokwaro G, et al. Clinical and neurophysiologic features of active convulsive epilepsy in rural Kenya: a population-basedstudy. Epilepsia. 2010;51:2370-6.

16. Sidenvall R, Forsgren L, Heijbel J. Prevalence and characteristics of epilepsy in children in northern Sweden. Seizure. 1996;5:139-46.

17. Braathen G, Theorell K. A general hospital population of childhood epilepsy. Acta Paediatr Scand. 1995;84(11):43-6.

18. Cavazzuti GB. Epidemiology of different types of epilepsy in school age children of Modena, Italy. Epilepsia. 1980;21:57-62.

19. Eriksson KJ, KoiviMco MJ. Prevalence, classification, and severity of epilepsy and epileptic syndromes in children. Epilepsia. 1997;38:1275-82

20. Stefienburg U, Hagberg G, Viggedal G, Kyllerman M. Active epilepsy in mentally retarded children: I. Prevalence and additional neuro-impairments. Acta Paediatr Scand. 1995:84(1):147-52.

21. Verrotti A, Mazzocchetti C. Beyond seizures - the importance of comorbidities in epilepsy. Pediatrics Nature Reviews. 2016;12:559-60

22. Tidman L, Saravanan K, Gibbs J. Epilepsy in mainstream and special educational primary school settings. Seizure. 2003;12:47-51.

23. Camfield PR, Camfield CS, Gordon K, Dooley JM. If' a first anti-epileptic drug fails to control a child's epilepsy, what are the chances of success with the next drug? J Pediatr. 1997;13(1):82.

24. Wirrell EC, Grossardt BR, Lily W-K, Nickels KC. Incidence and Classification of New-Onset Epilepsy and Epilepsy Syndromes in Children in Olmsted County, Minnesota from 1980-2004: A population-based study. Epilepsy Res. 2011;03:009.

25. Brorson LO, Wranne L. Long-term prognosis in childhood epilepsy: survival and seizure prognosis. Epilepsia. 1987:28(4):324-30.

26. Arts WF, Brouwer OF, Peters AC, Stroink H, Peeters EA, van Schmitz PI, et al. Course and prognosis of childhood epilepsy: 5-year follow-up of the Dutch study of epilepsy in childhood. Brain. 2004;127:1774-84.

27. Eddy CM, Rickards HE, Cavanna AE. The cognitive impact of antiepileptic drugs. Ther Adv Neurol Disord. 2011:4:385-407.

28. Jung JY, Cho JW, Joo EY, Kim SH, Choi KM, Chin J, et al. Cognitive effects of Topiramate revealed by standardized low-resolution brain electromagnetic tomography (SLORETA) of event-related potentials. Clin Neurophysiol. 2010;121:1494-501.

\section{Publisher's Note}

Springer Nature remains neutral with regard to jurisdictional claims in published maps and institutional affiliations.

Ready to submit your research? Choose BMC and benefit from:

- fast, convenient online submission

- thorough peer review by experienced researchers in your field

- rapid publication on acceptance

- support for research data, including large and complex data types

- gold Open Access which fosters wider collaboration and increased citations

- maximum visibility for your research: over $100 \mathrm{M}$ website views per year

At $\mathrm{BMC}$, research is always in progress.

Learn more biomedcentral.com/submission 